\title{
Design and Evaluation of an Instructional Solar Energy Technologies Lab
}

\author{
http://dx.doi.org/10.3991/ijoe.v7iS1.1730 \\ M. Al-Addous, C. B. Class \\ German Jordanian University, Amman, Jordan
}

\begin{abstract}
This paper presents a design for a solar energy lab that allows students to plan, install and evaluate different system architectures and gain relevant practical experiences. The addressed learning outcomes are analyzed based on the 13 learning outcomes defined by the Accreditation Board for Engineering and Technology (ABET) as well as based on the taxonomy levels of the cognitive domain after Bloom. In this paper we present a sample lab assignment and map its tasks to the learning outcomes and cognitive domains. First results of qualitative student feedback are equally presented.
\end{abstract}

Index Terms—solar energy; lab design; ABET

\section{INTRODUCTION}

Due to an ever increasing energy demand in industry, commerce and private households, increasing oil prices and the need to reduce greenhouse gases, renewable energy solutions become more and more important. This is also reflected in new strategies and changes in the energy portfolios of many countries. In order to implement the new energy portfolios technologies of renewable energy sources are becoming increasingly popular. These solutions need to be adapted to the availability of specific energy resources like wind and sun and to the specific characteristics of the energy use (e.g. day time only or 24/7). Further research is required for improving the performance of current technologies and storing and transporting energy for times and places when and where the renewable energy resource is not available. This development leads to an increasing demand for well trained and highly skilled engineers that can plan, implement and improve the use of green technologies. For this reason engineering programs with focus on renewable energies become more and more attractive and important for the future of our modern societies.

Engineering is a practical profession. Whereas sciences like physics are concentrating on understanding nature and natural laws, the main focus of the different engineering disciplines lies in developing and improving technical solutions to our daily problems by applying natural laws and using natural forces. Hands-on experiences and the development of practical skills are vital in engineering education. [1] states that "[o]ne of the unique features of an educational program in a practice-oriented discipline such as engineering is that of the live, hands-on laboratory and design experience.” Therefore, laboratories and practical assignments always played an important role in successful engineering curricula. But the use of laboratories alone does not guarantee educational programs that train qualified engineers. Laboratories must be designed to allow for experiments that are well aligned with the defined learning outcomes and can train and foster the necessary skills of the students.

Many physics, chemistry as well as computing labs provide enough resources for each student to carry out his experiments or her implementation tasks alone. Students can easily individualize their learning processes and gain relevant knowledge and skills. In other engineering fields, like e.g. solar energy, creating individual lab places and duplicating laboratory resources is often not possible. This can be due to the high costs and/or the large and specific space requirements for the relevant lab equipment. These labs equally must allow students to gain their individual experiences to develop the required knowledge and skills. New technologies and e-learning approaches are used to virtualize laboratory places, create simulation labs and allow more students to have access to practical experiences. Students may not have direct access to a physical laboratory as this might be located elsewhere and remote access must be provided [2]. These are valid and necessary extensions to real world labs, but it is equally of importance that students gain real world hands-on experiences with the technologies used. These experiences have different qualities as they involve real touch and feel experiences and students generally act more carefully as things can go wrong in the real world which may become costly or pose risks to the health of involved people. In order to train confident engineers that can handle the pressure often linked to dealing with dangerous material and with expensive and / or limited equipment the authors are convinced that it is highly desirable to enable all students to gain at least some experiences in real laboratories during their education.

Laboratories that allow for the education of qualified engineers must be well designed and carefully implemented. Financial and safety restrictions, space and location requirements and the alignment with the targeted learning outcomes have to be taken into account during the laboratory design. This poses many challenges.

In the Energy Engineering department of the German Jordanian University a solar energy lab has been successfully designed and implemented. It is used in the "Renewable Energy Resources Assessment” course. In this paper we will present the technical design of this lab and explain its alignment to relevant learning outcomes. We will structure the outcomes based on the 13 objectives that have been defined by the Accreditation Board for Engineering and Technology Accreditation Board for Engineering and Technology (ABET) [3] and discuss the cognitive domain levels according to Bloom's taxonomy of the cognitive domain [4]. We will present a sample task for students and 
map it to the different learning targets. First qualitative evaluation results will equally be presented.

\section{THE LABORATORY DESIGN}

[5] distinguishes three different kinds of laboratories. The purpose of an instructional laboratory is to provide an environment to students that enables them to learn activities that are necessary for the work of an engineer. These laboratory activities include training in handling laboratory equipment and measurement tools. The steps are well introduced or precisely described or demonstrated during lab sessions. Development laboratories play an important role in the development phase of a product as they allow for testing and verifying specific characteristics that are relevant for the correct functioning of a specific engineering product. In research laboratories more general questions can be answered that allow for a broader understanding of nature and technology. [5]

In universities all three kinds of laboratories are used. Instructional laboratories play an important role in the education and training of students. Development laboratories are used in some more advanced courses as future engineers must be prepared to design, implement and verify engineering solutions. Faculty uses development as well as research labs for applied and basic research. Graduate students and students participating in research projects may also be involved in the use of research labs.

Our lab has been designed to support all three functionalities: as an instructional lab it allows students to use measurement tools like pyranometers and collect and interpret measured data. The measurements are carried out manually as well as automatically using a data logger. As students design the storage tank in the thermal solar system by choosing the phase change material, its volume and its localization, the lab equally serves as (educational) development lab for optimal storage tanks. At the same time the lab is used for a research project that investigates the use and efficiency of different phase change and insulation materials that will be used to design storage tanks.

The laboratory is installed on top of one of our university buildings and consists of two different solar systems: a first system uses a flat-plate collector for the production of domestic hot water and a second one evacuated-tubes for domestic heating. The following two sections describe in detail the components of these two systems. Both laboratory parts are built out of off-the-shelf available components to examine and demonstrate the use of typical solar energy systems for private households.

\section{A. Flat-plate collector system}

The flat-plate collector, which is the basic unit in a thermal solar system, consists of an insulated metal box with glass or plastic cover and dark colored absorber plates. The absorbers are classified into two main categories (air-based and fluid-based). In fluid-based absorbers the fluid circulates through the collector tubes in order to transfer the absorbed heat, where the most commonly used fluid is water. On the other hand air-based collectors use air as a transfer medium instead of fluids.

Flat-plate collectors heat the circulating fluid to temperatures considerably less than the boiling point of water and are best suited for applications where the requested temperature is $30-70^{\circ} \mathrm{C}$ and/or for applications that require heat during winter months. Air-based collectors are typically used for heating buildings and drying crops. Liquid-based collectors may be glazed or unglazed. Glazed liquid-based collectors are the most common type of solar collectors for providing domestic and commercial hot water and for heating indoor swimming pools. Unglazed collectors are most often used for heating outdoor pools. A special type of unglazed collectors called a perforated plate collector is used to preheat ventilation air for commercial buildings or, in some cases, for drying crops. The schematic diagram of a flat plate collectorbased system is shown in Fig. 1.

The system is designed for the purpose of domestic hot water. It consists of the following components:

- Tank: this tank is mainly used to feed the system with water and is directly connected to a pump and automatic pump control.

- Water control pump/ automatic pump control: the water pump is mainly used to circulate water in the system, once triggered by the automatic pump control. The automatic pump control has a feedback unit which consistently measures the level of cold water and triggers pumping as soon as the water level in the storage tank is lower than a specified threshold.

- Flow meter A: connects the control water pump and the water storage tank, and measures the amount of water flowing through the system.

- Storage tank: stores the hot water resulting from the heat exchange process.

- Flat-plate collectors: convert solar radiation into heat. They are connected with a control panel and a measuring instrument. These flat-plate collectors are insulated and tilted at an angle of $45^{\circ}$. They can be connected in series or parallel manners.

- Control and measuring system: provides feedback by monitoring different parameters such as temperature, flow and pressure. The control unit is programmed to run the system between 6:30 am and 7:00 pm.

- Flow meter B: measures the flow from the storage tank to the flat-plate collector.

- Expansion valve: is used to relief the excess pressure in the system and, therefore, to avoid possible damages to the system components.

- PV (photovoltaic) module: feeds the system with the required amount of electrical power during the runtime of the system.

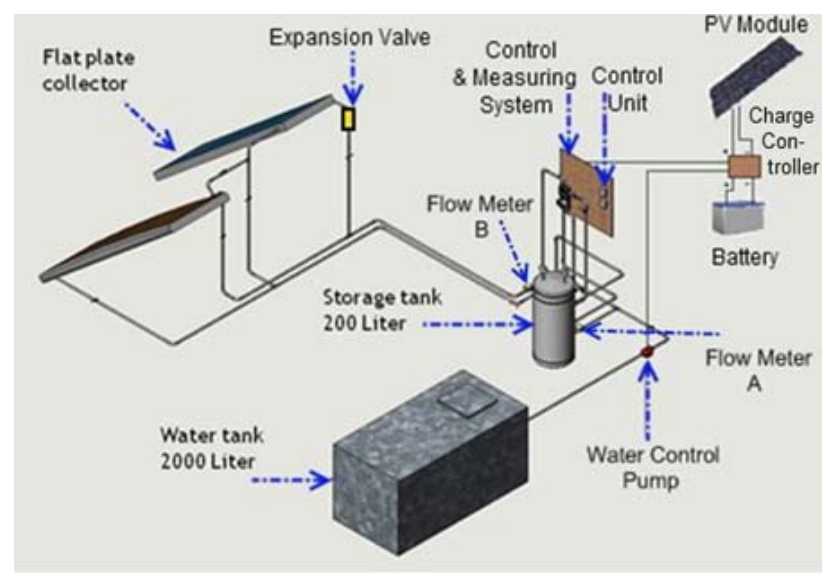

Figure 1. Flat-plate-based solar thermal system schematic diagram 
- Charge controller: controls the charging of batteries from the PV cells.

- Batteries: preserve the extra electrical power generated by the PV cells, and feed the system with the needed electrical power when necessary.

\section{B. Evacuated tube system}

The system using evacuated tubes is shown in Fig. 2.

The storage tank feeds the evacuated tubes with cold water. A circulation pump forces the cold water to circulate through the evacuated tubes. After circulating through the tubes, the hot water returns to the storage tank to heat the water and phase change material inside the tank. The hot water from the storage tank circulates then inside a radiator with the help of another circulation pump.

The system is designed for heating and domestic hot water and comprises the following components:

- Tank: this tank is mainly used to feed the system with water and is directly connected to a pump and automatic pump control.

- Control water pump/ automatic pump control: the water pump is mainly used to circulate the water in the system, once triggered by the automatic pump control. The automatic pump control has a feedback unit which consistently detects the level of cold water and initiates pumping as soon as the cold water level in the storage tank is below a specific desired value.

- Flow meter: connects the automatic pump control and the water storage tank, and measures the amount of water flowing through the system

- Storage tank: differs slightly from the one used for flat-plate systems, as phase change material (PCM) is included. The tank provides the evacuated tubes with cold water and stores the hot water instead. Further, it periodically feeds a radiator and a heat exchanger; providing them with hot water and receiving cold water in return.

- Phase Change Material (PCM): different types of phase change materials are used. These are filled in steel bottles inside the storage tank.

- Circulation pumps: two circulation pumps are required to circulate the water in the radiator and the evacuated tubes.

- Evacuated tubes: the evacuated tubes differ from the flat-plate collectors in that they have a higher efficiency. They are equally insulated and tilted at an angle of $45^{\circ}$.

- Panel radiators: water is heated in the storage tank and then forced through the front and back (depending on the type of radiator) panels of the radiators. Attached to the inside of the panels are flutes or fins which absorb heat through conduction. Panel radiators have the advantage of providing two forms of heat to a room. First, like baseboard heating, air is heated by the flutes inside the radiators and then convection takes place. Secondly, the hot water passing through the panels will emit radiant heat.

- Heat exchanger: is a device built for efficient heat transfer from one medium to another. The media may be separated by a solid wall, so that they never mix, or they may be in direct contact. Heat exchangers are widely used in space heating, refrigeration, air condi- tioning, power plants, chemical plants, petrochemical plants, petroleum refineries, natural gas processing, and sewage treatment.

As shown in Fig. 3 and Fig. 4 the systems designed, built and used in the lab comprise five main components, namely a solar collector, boiler, radiator, control system and the water storage tanks, within which a heat exchanger has been installed.

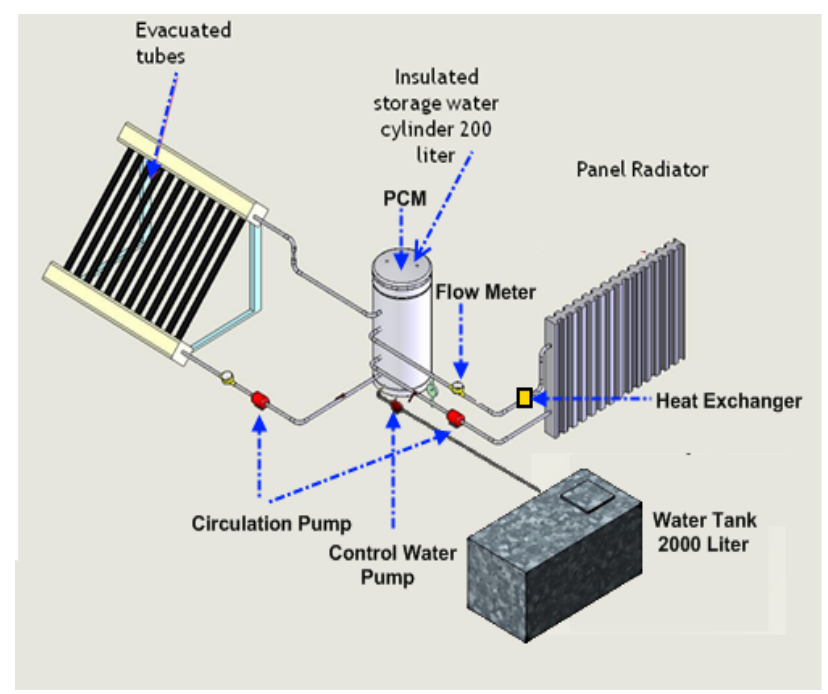

Figure 2. Evacuated tubes-based solar thermal system schematic diagram

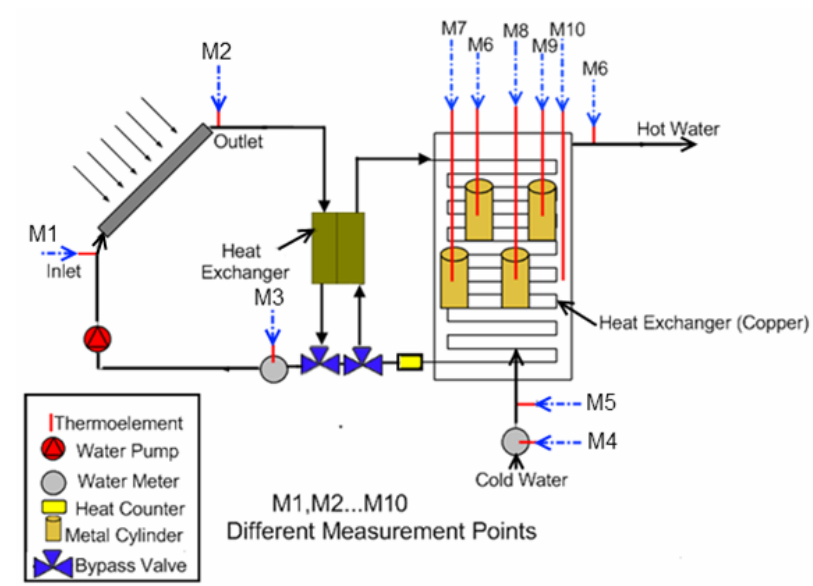

Figure 3. Schematic diagram of a flat plate collector

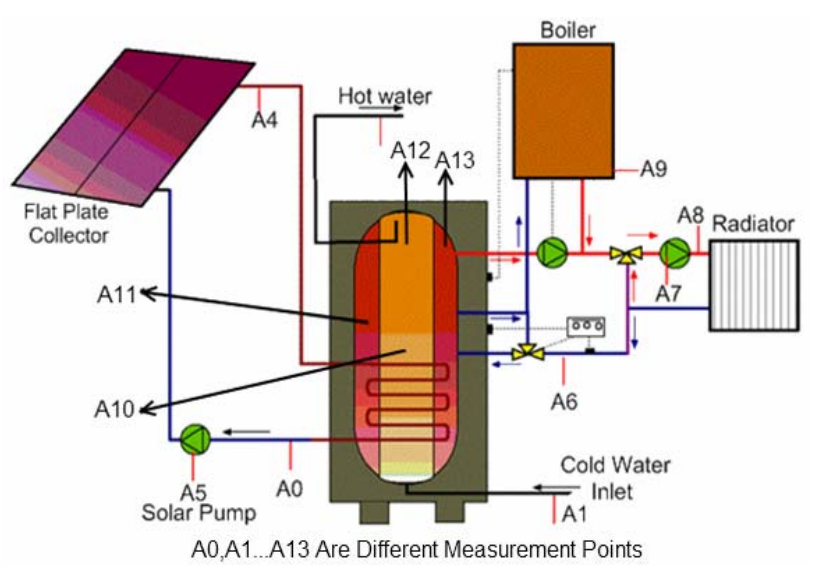

Figure 4. Solar thermal system 
Referring to these schematic diagrams; the water storage tanks consist of two concentric tanks, where one of them has been used for domestic hot water, while the second one can be used for space heating water. Finally and as indicated; the inlet and outlet water temperatures of solar collectors, radiator and water storage tanks will be measured. There are different locations to measure the temperatures such as M1, M2, ..., M10 in Fig. 3 and A0, $\mathrm{A} 1, \ldots . . . \mathrm{A} 13$ in Fig. 4. Different measure points equally allow for measuring the temperature of the phase change material. Other measuring points allow for collecting data about the flow rate through the collector and the radiation using different types of flow meters.

\section{GENERAL ANALYSIS OF THE LEARNING OUTCOMES OF LABORATORY EXPERIMENTS}

Teaching methods and student assignments need to be well aligned with the required learning outcomes and should address different cognitive domains. It is necessary to analyze targeted learning outcomes in order to achieve the educational goals as "clear learning objectives and assessment are essential in designing an effective learning system.” [6] In this section we will analyze the addressed learning outcomes.

\section{A. Fundamental learning objectives for instructional engineering laboratories}

We structure the learning outcomes of this analysis according to the 13 objectives defined by ABET (Accreditation Board for Engineering and Technology) [3]. Those objectives deal with cognition, the psychomotor domain and cognition combined with affection [5]. In the following part we will present examples of specific learning objective together with related experimental tasks in the solar energy laboratory.

\section{1) Instrumentation}

Students learn to accurately use different tools like pyranometers and anemometers as well as measurement software tools. This use is trained by requiring students to measure solar radiation, wind speed, humidity, flow rates etc. using manual and automatic measurements in the open air solar energy lab.

\section{2) Models}

Students apply the in lectures presented theoretical models to calculate solar radiation based on publicly available weather data (e.g. on the Internet) and identify the strengths and limitations of these models. Students calculate solar radiation based on the presented models and compare these results with the data they have been measuring during the experiments. The differences in values are discussed and analyzed.

\section{3) Experiment}

Students plan and evaluate measurement experiences. The lab design offers numerous locations to place the measurement tools. Students plan different setups, measure data and the performance of the system and analyze the results based on the measurement setup.

\section{4) Data Analysis}

Students are able to collect, analyze and interpret data. This is demonstrated by the setup of most experiments in the laboratory that require the measurement, analysis and interpretation of data. For data analysis different approaches are used and data is always measured manually and automatically in parallel. Students have to reflect on the meaning of collected data as well as on differences in manually and automatically measured values after each experiment.

\section{5) Design}

Students plan the storage tank according to given requirements, build a prototype and evaluate its performance. Students make decisions about the type of storage material (i.e. the phase change material), its volume and its location and have to implement a prototype based on their plans. They measure the performance of the designed system and evaluate it.

\section{6) Learn from failure}

Students learn to recognize unsuccessful outcomes due to their design decisions or measurement setups and plan improvements. During the lab experiments students make several design decisions related to the design of the storage tank as well as to the design of the measurement setup. Those designs are cyclic so that students learn from weaknesses in their first approach, analyze them and have the chance to improve the design to observe the improved performance.

\section{7) Creativity}

Students apply independent thoughts to solve real world problems. During the lecture necessary input is given to the students to understand the theory and be able to design the experimental measurement setup as well as to plan the use of the phase change material in the storage tank. During the design process students use their knowledge without being closely directed. This leaves them space to apply their own problem solving skills and find creative solutions. Students then will evaluate their solutions themselves based on measured data.

\section{8) Psychomotor}

Students can select and operate the required engineering tools. As engineering is a practical discipline it is important that students do not only observe the use of tools but gain personal experience in their handling (touch and feel). During the presented course, many different experiments are based on the application of the different measurement tools. This gives all students sufficient possibilities to practice their psychomotoric skills.

\section{9) Safety}

Students recognize safety and health relevant issues related to the technological processes and activities. During the lab experiments students handle materials that require precautions for their personal health, e.g. when dealing with the hot water in the water tank or when using gloves to protect the skin from direct contact with the different storage materials. Students also are responsible to operate manually the control unit that regulates the pressure in the whole system.

\section{0) Communication}

Students present their laboratory work orally and in written form. Forms are provided to the students to protocol measurements and provide their reflections. At the end of each experiment students write a short report that summarizes and interprets the experimental results and data. They also discuss those results orally with the responsible professor.

\section{1) Teamwork}

Students learn to work effectively in a team, assign responsibilities and respect deadlines. In the presented 
course all experiments are carried out in teams of 3 to 4 students. As resources are limited students have to distribute and assign roles, e.g. who is manipulating the manual measurement tools and who is downloading the data from the automatic measurements. As each experiment has a given deadline, students continuously practice to respect given deadlines and learn that each team member must accept his responsibility in order to allow for the whole team to succeed.

\section{2) Ethics in the lab}

Students learn to report information objectively. There will always be differences between the manually and the automatically measured data. The fact that this is taken for granted and discussed without necessarily blaming the person, who took the measurement, will increase students' self-competency to report their data in an objective way and not to falsify it. Ethics in the (instructional) lab also depend on how the instructors react to "weird" data or to errors students make. The described lab is understood as a platform where students can make such errors in order to learn. The learning situation is therefore designed to encourage students to behave ethically as they will not be punished in case of suboptimal results.

\section{3) Sensory awareness}

Students use their human senses to gather information. Even when tools are used, the human senses of students are involved in all data gathering tasks. Equally differences between analog and digital information are discussed when using the tools. This is an important topic for students as human sensors generally perceive in an analog and not a digital form.

The experiments in the described lab include learning outcomes in the field of all 13 objectives described by ABET and are therefore well aligned with requirements to effective laboratory education.

\section{B. Cognitive domains}

For the analysis we will base on the taxonomy levels of the cognitive domain after Bloom that have been finalized and published in 1956 [4]. Their original ordering has been knowledge, comprehension, application, analysis, synthesis, and evaluation. It is a hierarchical ordering which means that without being able to comprehend a given subject it cannot be applied nor can analyses in this subject domain be performed. There have been discussions whether the ordering of the last two levels should be reversed [4] but this is not relevant for the following analysis of the lab experiments. We will discuss how each of the cognitive domains is addressed during the lab experiments.

\section{1) Knowledge}

In the knowledge domain it is important to recall or recognize given information and ideas. As different tools are introduced during the labs, students will learn their purpose, main characteristics and requirements for using them safely.

\section{2) Comprehension}

In this cognitive domain students must be able to e.g. translate or explain information based on their prior knowledge. The lab and experiment settings require students to explain the system design of the flat-plate and the evacuated-tubes solar system. Simple knowledge of the parts and their characteristics are not sufficient to explain and describe the system.

\section{3) Application}

Students select data and information to design the experimental measurement setup and implement it by performing the measurements themselves or automatically using the data logger. Equally students apply theories and models in order to calculate e.g. solar radiation based on specific weather data.

\section{4) Analysis}

Large amounts of data are collected and analyzed during the different experiments. The analysis does not only include the analysis of a given data set, but also the comparison between manually and automatically collected data.

\section{5) Synthesis}

Students design the storage tank, i.e. plan the use of the phase change material in the storage tank based on collected data and previous knowledge. This design is new to the students. They develop a prototype to be implemented in the solar energy lab.

\section{6) Evaluation}

Students evaluate the accuracy of their measurement design as well as the performance of the storage tank. For the storage tank design recommendations for improvements are given and carried out by adapting the design and re-evaluating the modified design (cyclic design process). The comparison of the manually and automatically collected data sets equally involves assessment and an evaluation of the differences. It can be placed into this cognitive domain.

The experiments that are carried out in the described solar energy lab include tasks related to all cognitive domain levels in Bloom's taxonomy. This is an important result as especially the higher level domains are important for developing relevant problem solving skills and are not addressed by every didactical teaching method. E.g. classical classroom teaching and lecturing often lack to address these domains sufficiently.

\section{ANALYSIS OF A SAMPLE LABORATORY EXPERIMENT}

In this section we present a sample lab experiment of the first half of the term and analyze it with respect to the 13 learning outcomes and the different cognitive domains. We will show that one single lab experiment can tackle most of the learning outcomes and cognitive domains.

In this sample lab experiment students analyzed a solar system to support and meet the hot water needs of four persons during summer months, given that:

- Average amount of daily requirements per each person is: 70 liter per day.

- Hot water temperature is $45^{\circ} \mathrm{C}$

- Cold water temperature is $10^{\circ} \mathrm{C}$

For the solution students have to apply two different calculation methods using measured data. The following different values have to be measured in order to solve this assignment.

- Inlet and outlet temperatures of the collectors (flatplate and evacuated-tubes collectors).

- The fluid (water) temperatures inside the storage tank at different levels (upper, middle and lower parts).

- Phase change material's temperature. 
- Ambient temperature

- The solar radiation on the horizontal plane and on a plane tilted with the same tilt angle as the solar collectors.

- The flow entering the system (cold water from the water tank)

- The flow through solar collectors

- The flow exiting the system (the used hot water)

- The energy transferred to the radiator and to the heat exchanger.

The students have to determine the energy in the system and its efficiency. All measured data must be noted using a specific form (see Fig. 5).

All the required data must be measured manually then compared with those taken automatically. The automatically measured data are sent to the computer, by connecting the sensors and devices with a data logger. This data logger saves the data, which is taken every 20 seconds, and calculates an average value for every five minutes interval. These values are transferred to the computer when connected.

The sample lab experiment addresses the following fundamental learning objectives:

1. Instrumentation and psychomotor: in this experiment students used many different tools like thermometers, pyranometers, voltmeters, heat meters and flow meters for hot and for cold water.

2. Models: for the calculation students applied solar radiation equations as well as equations for energy storage in water and phase change materials.

3. Experiment: the student teams had to plan and carry out the experiment and evaluate the results.

4. Data Analysis: students analyzed the measured data and their differences from the theoretically calculated data.
5. Learn from failure and ethics in the lab: depending on the student group some errors were made. E.g. sometimes the calculated efficiency was higher than $100 \%$. In this case the professor helped the students to find the errors in measurements and calculations. Students were not punished, which increases their willingness to honestly report measurement results and not falsify data.

6. Creativity: as a result of the experiment the students had to discuss the used phase change material and make suggestions for a better solution.

7. Safety: students received a leaflet with the necessary precautions. Several precautions were relevant for the described lab experiment, like the careful handling of hot water and steam.

8. Communication: students used the written form to communicate the experiment results. Each student wrote an individual report about the experiment and discussed it with the professor.

9. Teamwork: students worked on the lab experiment in teams and distributed the measurement tasks themselves to the team members.

The specified lab experiment contains elements that target the knowledge, comprehension, application, analysis and evaluation cognitive domain of Bloom's taxonomy.

The described lab experiment targets 11 from the 13 learning objectives and 5 of the 6 cognitive domains. Other experiments were designed to equally target the other learning objectives and domains. As all experiments focused on many different learning outcomes, the defined learning objectives by ABET as well as the cognitive domains could be thoroughly covered.

\begin{tabular}{|c|c|c|c|c|c|c|c|c|c|c|}
\hline$\Delta$ & A & B & C & D & E & $\mathrm{F}$ & G & H & 1 & J \\
\hline 1 & & \multicolumn{7}{|c|}{ German Jordanian University } & \multirow{3}{*}{\multicolumn{2}{|c|}{ 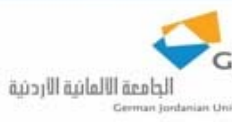 }} \\
\hline 2 & & & & & & & & & & \\
\hline 3 & & & & & & & & & & \\
\hline 4 & \multicolumn{2}{|l|}{ Date: } & & & & \multicolumn{2}{|l|}{ Lab exp. Number: } & & & \\
\hline 5 & \multicolumn{2}{|c|}{ Group number: } & & & & \multicolumn{4}{|l|}{ Experiment title: } & \\
\hline 6 & Name: & & & & & & & & & \\
\hline \multicolumn{11}{|c|}{7} \\
\hline 8 & \multicolumn{2}{|c|}{ collector type: } & \multicolumn{3}{|c|}{$\downarrow$} & & & & & \\
\hline 9 & \multicolumn{2}{|c|}{ case number: } & \multirow{2}{*}{\multicolumn{3}{|c|}{$\downarrow$}} & & & & & \\
\hline \multicolumn{8}{|l|}{10} & & & \\
\hline 11 & Time & $\mathrm{G}$ at $\mathrm{H}$ & G at $45 \mathrm{deg}$ & $T$ ambient & $T$ in, collector & T out, collector & T tank, upper & $\mathrm{T}$ tank, middle & flow & $Q^{\prime}$ \\
\hline 12 & & {$\left[\mathrm{~W} / \mathrm{m}^{\wedge} 2\right]$} & {$\left[\mathrm{W} / \mathrm{m}^{\wedge} 2\right]$} & {$[\operatorname{deg} C]$} & {$[\operatorname{deg} \mathrm{C}]$} & {$[\operatorname{deg} C]$} & {$[\operatorname{deg} C]$} & [deg C] & [L/sec] & {$[\mathrm{W}]$} \\
\hline \multicolumn{11}{|l|}{13} \\
\hline \multicolumn{11}{|l|}{14} \\
\hline \multicolumn{11}{|l|}{15} \\
\hline \multicolumn{11}{|l|}{16} \\
\hline \multicolumn{11}{|l|}{17} \\
\hline \multicolumn{11}{|l|}{18} \\
\hline \multicolumn{11}{|l|}{19 . } \\
\hline \multicolumn{11}{|l|}{20} \\
\hline \multicolumn{11}{|l|}{21} \\
\hline 22 & & & & & & & & & & \\
\hline 23 & & & T & 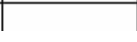 & & & & & & \\
\hline
\end{tabular}

Figure 5. Form for the laboratory measurements during the described experiment 


\section{ORganizational Aspects of the LAB UsE}

As previously mentioned the lab is used as instructional, development and research lab. In the "Renewable Energy Resources Assessment" course students use the lab for instructional purposes to train their measurement skills and become acquainted with the tools. They equally design and develop solutions for the storage tanks and evaluate them. Thus during the course the lab use is defined by two different roles. As the lab has two different systems, the flat-plate and the evacuated tubes-based systems, two different student groups can work in parallel with the technical equipment in the lab. In order to allow for more student groups, we equally use simulations of an evacuated-tubes based and a flat-plate based solar system by Dr. Valentin EnergieSoftware GmbH. ${ }^{1}$ The simulation allows for the design and evaluation of solar energy systems. Specific lab assignments are developed for the use with the simulation software. In the simulation software weather data as well as measured data are stored. This allows students to theoretically calculate data and compare them with the simulated measurement data. The differences will be based on the same effects as in the lab, e.g. due to clouds, the ambient temperature or dust in the air. So students can equally perform analysis, design and evaluation tasks using the simulation.

The research project examines different phase change as well as insulation materials. The research is carried out in the same lab that is used by the students and is based on measurements in the system. All automatic measurements are performed daily from 6:30 am to 7:00 pm. As in some experiments students modify the system design by changing volume and location of the phase change material in the storage tank, the researchers check in detail the current system after each lab and calibrate the measured data with respect to the changes made by the students. Some of the changes will be undone to set the system back to its initial state. This is of course a suboptimal solution but due to the fact that the solar energy lab is currently only used during one afternoon per week for educational purposes, enough valid data is collected for the research project and there is no absolute need to duplicate the expensive components.

\section{EVALUATION}

The solar energy has been used so far in three semesters in row. The experiences so far are promising. The students became more confident and experienced in using measurement tools like pyranometers, flow meters, heat meters, thermometers, etc. and the quality of the measurement results has increased. Students have learned to compare theoretical and experimental results and have gained experience in evaluating results on their own. Students became more confident of handling delicate phase change materials like salt hydrate and observed the different safety requirements.

Improvements in students' ability to analyze the observed facts and evaluate the results independently without guidance of the professor could be noted. Equally the team skills improved visibly. Students have developed relevant skills they will use in their future roles as engineers which increased their self-confidence.

Students were motivated and discussed a lot. They were very active during the lab and interested in having the chance to apply their theoretical knowledge practically. This helped bridging the gap between theory and practice. They were willing to spend a lot of time in the lab and also stayed after the official lab time has finished.

The lab equally has been used in one graduation project which was successfully completed. During this project the two systems were compared and first results of the comparison of phase change materials have been obtained.

The official evaluation forms of our institution are not suitable to evaluate in detail the targets obtained by using this specific lab. Therefore we evaluated the course qualitatively in spring term 2011 by asking students. We wanted to verify how the 13 different learning objectives according to ABET could be addressed. The evaluation consisted of in total 33 different questions. We have defined 6 different groups of questions that were focusing on specific learning objectives.

In a first group four different questions addressed instrumentation, safety and psychomotor. We asked about the tools used, precautions made and whether the confidence to use tools of students increased. The next 13 questions were referring to models, data analysis, sensory awareness and learning from failure. We asked students which models they applied, how they performed measurements and analysis, which difficulties they faced, how much degree of freedom they experienced, whether they compared results of measurements (e.g. temperature) with body sensations and whether they feel more confident to apply models. The next group of questions was related to design, creativity and experiments. It consisted of 5 questions about the perceived degree of freedom in design and experiment planning, the required creativity and whether the experiments and tasks increased students' confidence in being a future engineer. Three questions were related to the fields of communication and teamwork. The questions were addressing the communication forms, feedback from the professor as well as the improvement of teamwork skills in the lab. To evaluate the students' ideas of ethics in the lab we provided 6 statements to the students and asked them to which degree they agreed with these statements (Fig. 6). With these statements we did not evaluate the lab ethics of the students but wanted to know whether they are sensitized to inform objectively even if the measurement results are unexpected.

In the last part of the evaluation we asked students about the three skills and competences they improved most and about skills and competences that should be trained more.

1. If the time is too short to perform all measurements, we can also use calculated data.

2. It is important to clearly mark data that is calculated as opposed to being measured.

3. Measurement results cannot be trusted, they always must be validated.

4. If measured results are different from the theoretically calculated ones, the measurement is wrong.

5. As measurement data may be wrong, it is better to use the theoretically calculated data.

6. Data outliers are always wrong and can, therefore, be ignored.

Figure 6. Statements related to ethics in the lab 
As the number of students that have participated in this evaluation is limited, we do not yet have significant results. But the preliminary results indicate that we could indeed tackle all intended learning outcomes. Interestingly the degrees of freedom during the experiments have been perceived very differently by different students. This might be due to different expectations or to the organization and task distribution of the different teams. We will continue the evaluations to obtain more significant results.

\section{SUMMARY AND CONCLUSION}

In this paper we have presented the design of a solar energy lab. It is used as instructional and development laboratory for students and as a research laboratory for faculty. The lab provides two systems, one using flat-plate and the other using evacuated tubes solar collectors. The systems are designed for domestic heating and domestic hot water supply. The systems are built out of off-the-shelf components. We have described the systems and discussed how this lab is used for different purposes in parallel. The students use the lab to understand the components and to measure numerous values using different tools like pyranometers, flow meters, heat meters, thermometers, etc. As in parallel to the manual measurements automatic measurements are carried out, students analyze and discuss the different values. Equally they compare the values with data that are calculated based on the publicly available weather data in the Internet and theoretical models. Students make decisions about where to place the measurement tools and about the measurement setup. In addition students have the possibility to modify the design of the storage tanks by changing the phase change material, its quantity and its location. Students can therefore use this lab not only as instructional but also as development laboratory.

As research lab the systems in the solar energy lab provide an environment to study different phase change and insulation materials. We have discussed how research and educational use can take place in the same lab. Once the results of the current research project are finalized, students will have the chance to use different insulation materials in their storage tank design experiments as well.

We have analyzed the use of the lab by mapping objectives and experimental tasks to the 13 learning outcomes that have been defined by ABET for engineering labs [3] as well as to the six levels of the cognitive domain that are defined in Bloom's taxonomy [4]. We have presented a sample lab experiment to demonstrate the numerous measurements students perform in this lab. They have to design the experimental measurement and to apply models and analyze measurement and theoretical results. We have analyzed this specific experiment in more detail and could show that all learning objectives as well as all taxonomy levels can indeed be addressed in the current lab design.

We have been successfully using this lab for three courses so far. Students are highly motivated and are suc- cessful in their experiments. We equally have used this lab in a graduation project. In spring 2011 a first qualitative analysis of the lab experiments has been carried out. The evaluation results confirm our claim that all learning targets can be addressed by the lab.

\section{REFERENCES}

[1] I. Gustavson, K. Nilsson and Th. Lagö: “On physical experiments and individual assessment of laboratory work in engineering education”, MEDES The International Conference on Management of Emergent Digital EcoSystems, October 2009.

[2] I. Michaelides1, P. Eleftheriou and D. Müller, "A remotely accessible solar energy laboratory - A distributed learning experience”, 1st Remote Engineering and Virtual Instrumentation International Symposium (REV'04), Villach (Austria), 28 - 29 September 2004

[3] L.D. Feisel and G. D. Peterson. “A colloquy on learning objectives for engineering education laboratories”. American Society for Engineering Education Annual Conference \& Exposition, 2002.

[4] W. Huitt. "Bloom et al.'s taxonomy of the cognitive domain". Educational Psychology Interactive. Valdosta, GA: Valdosta State University, 2009. Retrieved $23^{\text {rd }}$ of June 2011 from http://www.edpsycinteractive.org/topics/cogsys/bloom.html

[5] L. D. Feisel and A. J. Rosa. "The role of the laboratory in undergraduate engineering education.”, Journal of Engineering Education, January 2005, pp. 121-130

[6] N. S. Edward, "The role of laboratory work in engineering education: student and staff perceptions”, International Journal of Electrical Engineering Education, 39/1, pp. 11-19.

\section{AUTHORS}

M. Al-Addous studied Energy Technology at Technical University (TU) Freiberg, Germany, and obtained his $\mathrm{PhD}$ in Energy Engineering from the same university. From 2002 to 2006 he worked as scientific and research assistant in the Institute of Heat Engineering and Thermodynamics (IWTT), TU Freiberg, Germany. From 2007 to 2009 Dr. Al-Addous was in the Department of Metallurgy and Measurement, Development of Testing Specifications and Methods at the Royal Scientific Society, Amman. In 2008 he joined the Energy Engineering Department at the German Jordanian University in Amman, Jordan. (Mohammad.Addous@gju.edu.jo).

C. B. Class studied Business Informatics at the University of Mannheim, Germany, and made her $\mathrm{PhD}$ in the Computer Engineering and Networks Laboratory at the Swiss Federal Institute of Technology in Zurich, Switzerland. From 1999 to 2008 she was professor for computer science at the Lucerne University of Applied Sciences and Arts in Switzerland. In 2008 she joined the computer science department at German Jordanian University in Amman, Jordan. Dr. Class has several certificates and degrees in didactics. (Christina.Class@gju.edu.jo)

The laboratory described in this paper has been implemented with the help of a Support to Research and Development (SRTD) in Jordan. This article is an extended and updated version of the authors' paper "Acquiring Expertise in a Lab for Solar Energy Technologies”, IEEE EDUCON 2011. Received, June $29^{\text {th }}$, 2011. Published as resubmited by the authors August $2^{\text {nd }}, 2011$. 